\section{Commentary: Accomplishing mission impossible: Transcatheter mitral valve-in-valve replacement for failing intra-atrial bioprosthetic mitral valves}

\author{
J. Trent Magruder, MD, ${ }^{a}$ Pradeep K. Yadav, MD, ${ }^{\mathrm{b}}$ and \\ Vinod H. Thourani, MD
}

Evidence continues to accumulate that transcatheter mitral valve-in-valve replacement (TMViV) is a safe and effective therapy for failing mitral bioprotheses. The Transcatheter Valve Therapy Registry analysis of 1529 patients undergoing TMViV with a balloon-expandable valve has shown an incredible procedural success in $96.8 \%$ of patients, with a 5.4\% 30-day mortality and meaningful improvements in New York Heart Association functional classification at 1 year. ${ }^{1}$ Falasa and colleagues ${ }^{2}$ describe a transseptal TMViV with an interesting twist: Due to severe mitral annular calcification (MAC), the existing 25$\mathrm{mm}$ bioprosthesis was implanted into the left atrium using an 8 -mm polyethylene terephthalate graft collar. ${ }^{2}$ This approach using the valve in collar has been previously described as a technique to avoid disrupting MAC and potentially the atrioventricular groove in challenging mitral valve replacement cases. ${ }^{3,4}$ Falasa and colleagues ${ }^{2}$ should be congratulated for describing the possibilities of performing the TMViV implant within this collar graft. The authors emphasize the importance of 3-dimensional transesophageal echocardiography to facilitate a high transseptal puncture, which is crucial given the existing valve's position $2.5 \mathrm{~cm}$ above the native annulus in the

From the a Department of Cardiovascular Surgery, Piedmont Heart Institute, Athens, $\mathrm{Ga} ;{ }^{\mathrm{b}}$ Division of Cardiology and ${ }^{\mathrm{c}}$ Department of Cardiovascular Surgery, Marcus Valve Center, Piedmont Heart Institute, Atlanta, Ga.

Disclosures: Dr Yadav and Dr Thourani have been advisors and participated in research for Abbott Vascular and Edwards Lifesciences. The other author reported no conflicts of interest.

The Journal policy requires editors and reviewers to disclose conflicts of interest and to decline handling or reviewing manuscripts for which they may have a conflict of interest. The editors and reviewers of this article have no conflicts of interest.

Received for publication July 26, 2021; revisions received July 26, 2021; accepted for publication July 30, 2021; available ahead of print Aug 4, 2021.

Address for reprints:Vinod H. Thourani, MD, Department of Cardiovascular Surgery,

Marcus Valve Center, Piedmont Heart Institute, 95 Collier Rd, Suite 5105, Atlanta,

GA 30308 (E-mail: vinod.thourani@ piedmont.org).

JTCVS Techniques 2021;10:271-2

2666-2507

Copyright (c) 2021 The Author(s). Published by Elsevier Inc. on behalf of The American Association for Thoracic Surgery. This is an open access article under the CC BY-NC-ND license (http://creativecommons.org/licenses/by-nc-nd/4.0/).

https://doi.org/10.1016/j.xjtc.2021.07.023

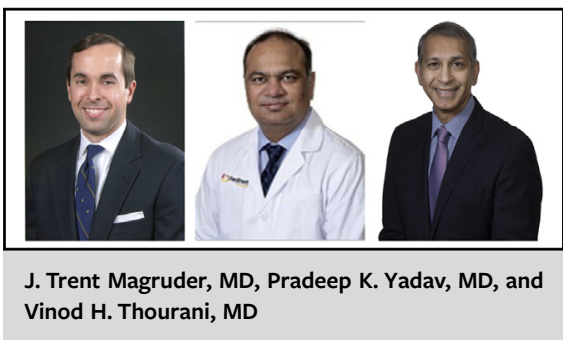

\author{
CENTRAL MESSAGE \\ Transcatheter mitral valve-in- \\ valve replacement appears \\ feasible for intra-atrial mitral \\ bioprostheses as part of a \\ conduit and may spare patients \\ with severe MAC from another \\ difficult, if not impossible, \\ reoperation.
}

left atrium. One disadvantage of this technique is that any paravalvular regurgitation at the level of the annulus (at the site of the MAC) would not be addressed with the TMViV. Fortunately, this patient had mild-moderate paravalvular regurgitation at the site of the MAC, which was unchanged following the procedure, and deemed not significant enough to merit intervention.

This report, taken in context with the promising Transcatheter Valve Therapy Registry TMViV data, crystalize the emerging transcatheter treatment approach to patients with failed mitral valve bioprosthesis. Patients with structural valve deterioration following bioprosthetic mitral valve replacement do poorly without intervention, but also are often at high to extreme surgical risk for a reoperation. Current operative mortality for reoperative mitral surgery runs in excess of $10 \% .^{5}$ Meanwhile, the finding of severe MAC has been associated with 15\% 1-year mortality after the index mitral operation alone; one imagines the surgical situation would be even worse following a reoperation. ${ }^{6}$ Patients who have received an intra-atrial surgical mitral valve, and who therefore have severe MAC, are often at severely if not prohibitively elevated risk for a reoperation - not to mention that there may be no viable reconstructive option to excise a failing valve and reimplant a new valve. Fasala and colleagues demonstrate that high-risk patients can be spared a reoperative mitral valve surgery using an elegant transcatheter solution, even when the existing bioprosthesis sits $2.5 \mathrm{~cm}$ higher 
than the native annulus. This contribution highlights the flexibility and versatility of TMViV even for unusually positioned valves, and again demonstrates the ability of transcatheter valve therapies to improve outcomes for patients whose surgical options are limited, if they exist at all. With TMViV as an option, patients might be saved from a surgical mission impossible.

\section{References}

1. Whisenant B, Kapadia SR, Eleid MF, Kodali SK, McCabe JM, Krishnaswamy A, et al. One-year outcomes of mitral valve-in-valve using the SAPIEN 3 transcatheter heart valve. JAMA Cardiol. 2020;5:1245-52.
2. Falasa MP, Tartara P, Matar R, Jones TE, Anderson RD, Beaver TM. Transseptal mitral valve-in-valve replacement of intra-atrial mitral prosthesis in a patient with severe mitral annular calcification. J Thorac Cardiovasc Surg Tech. 2021;10: 266-8.

3. Nataf P, Pavie A, Jault F, Bors V, Cabrol C, Gandjbakhch I. Intraatrial insertion of a mitral prosthesis in a destroyed or calcified mitral annulus. Ann Thorac Surg. 1994;58:163-7.

4. Santana O, Lamelas J. Intra-atrial placement of a mitral prosthesis in a patient with severe mitral annulus calcification: a case report. Heart Surg Forum. 2010;13: E25-7.

5. Mehaffey HJ, Hawkins RB, Schubert S, Fonner C, Yarboro LT, Quader M, et al. Contemporary outcomes in reoperative mitral valve surgery. Heart. 2018;104: 652-6.

6. Uchimuro T, Fukui T, Shimizu A, Takanashi S. Mitral valve surgery in patients with severe mitral annular calcification. Ann Thorac Surg. 2016;101:889-95. 